\title{
Privatizacija na področju varnosti cestnega prometa - primer prometnih dovoljenj
}

UDK: 351:658:656.1

Primož Pevcin, Iztok Rakar

Fakulteta za upravo, Univerza v Ljubljani

primoz.pevcin@fu.uni-lj.si; iztok.rakar@fu.uni-lj.si

\section{IZVLEČEK}

Eden od osnovnih pogojev za varnost cestnega prometa je tehnična brezhibnost vozil. Glede na to, da nadzor izpolnjevanja tega pogoja zahteva specifična strokovna znanja in tehnično opremo, hkrati pa se država srečuje s fiskalnimi omejitvami, je razumljivo, da je država za izvajanje te naloge pooblastila ustrezno usposobljene subjekte zasebnega sektorja, pri čemer je nanje prenesla tudi klasične oblastne naloge dovoljevanja udeležbe vozil v prometu (pri čemer je hkrati tudi sama ohranila izvajanje teh oblastnih nalog). Podatki o številu opravljenih storitev izdajanja in podaljšanja veljavnosti prometnega dovoljenja za motorna vozila v Sloveniji so pokazali, da velika večina uporabnikov to storitev zaradi enostavnosti in nižjih oportunitetnih stroškov opravi pri pooblaščenih subjektih zasebnega sektorja, kar govori v prid popolni privatizaciji pri klasičnem upravnem izvajanju te oblastne naloge.

Ključne besede: birokracija, ravnanje, birokratski output, pritožbe državljanov

\section{Uvod}

Področje cestnega prometa $\vee$ zadnjih desetletjih zaznamujejo po eni strani hiter tehnološki razvoj vozil in prometne infrastrukture ter naraščanje števila vozil, udeleženih $v$ prometu, po drugi strani pa prometne nesreče in njihove posledice z izgubami človeških življenj in družbenogospodarsko škodo. Zaradi 
Primož Pevcin, Iztok Rakar

Privatizacija na področju varnosti cestnega prometa primer prometnih dovoljenj

teh negativnih posledic regulira področje prometa država, ki skuša na ta način doseči čim večjo prometno varnost. ${ }^{1}$

Eden od osnovnih pogojev za varnost cestnega prometa kot ene od temeljnih kakovosti prometnega sistema je tehnična brezhibnost vozil. Ker sta za nadzor izpolnjevanja tega pogoja potrebna specifično strokovno znanje in draga tehnična oprema, je razumljivo, da je država za izvajanje te naloge relativno zgodaj pooblastila subjekte zasebnega sektorja, ki so izpolnjevali kadrovske, tehnične in druge pogoje. Nanje je nato zaradi poenostavitve postopkov za uporabnike storitev prenesla tudi klasične oblastne naloge, s katerimi je dovoljevala, da je $v$ prometu udeleženo tehnično brezhibno vozilo .

Temeljni namen tega prispevka je podati ekonomsko analizo trenutno veljavne ureditve izdaje oziroma podaljševanja veljavnosti prometnega dovoljenja $\vee$ Sloveniji in predlagati izboljšave te ureditve.

\section{Pravna ureditev pogojev za udeležbo vozil v prometu}

\subsection{Uvod}

Pravna ureditev pogojev, ki jih morajo za udeležbo v prometu izpolnjevati vozila, je sestavni del pravne ureditve varnosti cestnega prometa. Ta sklop pravil je bil $\vee$ Sloveniji $\vee$ zadnjih letih predmet številnih sprememb. Kot kaže analiza obrazložitev zakonodajnih predlogov, je bil namen teh sprememb naslednji: zmanjševanje stroškov, večja učinkovitost sistema, poenostavitev postopkov in približevanje storitev njihovim uporabnikom. ${ }^{2}$

$1 \mathrm{~V}$ Evropski uniji (EU) v prometnih nesrečah letno umre več kakor 40.000 ljudi, 1.700 .000 pa jih utrpi poškodbe. Kazalci števila prometnih nesreč s smrtnim izidom kažejo, da je število nesreč $s$ smrtnim izidom na 1.000 .000 prebivalcev v Sloveniji za $44 \%$ višje od povprečja držav članic EU, kar nas uvršča na 20. mesto med 25 članicami EU. Trend števila mrtvih v prometnih nesrečah $v$ zadnjih desetih letih sicer upada in je $45 \%$ manjše kot leta 1995 . Ne glede na to evalvacija nacionalnega programa za obdobje 2002-2005 kaže, da se je prometna varnost $v$ zadnjih dveh letih poslabšala (osnutek resolucije o nacionalnem programu varnosti cestnega prometa za obdobje 2007 - 2011, str. 6; podatki se nanašajo na obdobje pred širitvijo EU na 27 članic).

2 Nekaj primerov obrazložitev: "/.../ v primerjavi z obstoječim stanjem /.../ bo prispeval $k$ približno $30 \%$ zmanjšanju sredstev, ki so jih občine porabile za upravne postopke« (obrazložitev predloga ZVCP z dne 19. 1. 1995, Poročevalec DZ, 1995, str. 16), "Naveden prikaz in zapisane ocene kažejo, da je takšen sistem za državo neracionalen, za državljana pa predstavlja nezadovoljiv servis", "Cilji predloga zakona so: /.../ ne povečati stroškov dela državne uprave 


\section{Privatizacija naž Pevcin, Iztok Rakar primer prometnih dovoljenj}

\subsection{Pozitivnopravna ureditev pogojev za udeležbo vozil v prometu}

Veljavno pravno ureditev udeležbe vozil $\vee$ cestnem prometu po zakonu o varnosti cestnega prometa (ZVCP-1-UPB4) ${ }^{\mathbf{3}}$ bi lahko najbolj poenostavljeno povzeli na naslednji način: vozilo sme biti udeleženo $v$ cestnem prometu, če je registrirano, če je zanj izdano veljavno prometno dovoljenje in je označeno $s$ predpisanimi registrskimi tablicami. ${ }^{4}$

Prometno dovoljenje je upravna odločba, torej oblastni pravni akt, s katerim država oziroma od nje pooblaščeni subjekt dovoli, da se vozilo lahko uporablja, kar lahko primerjamo z uporabnim dovoljenjem $v$ skladu z zakonom o graditvi objektov (glej ZGO-1).

$\checkmark$ postopku izdaje oziroma podaljševanja veljavnosti prometnega dovoljenja se praviloma ${ }^{\mathbf{5}}$ preverja tudi tehnično brezhibnost vozila. Tako stanje vozila se dokazuje z dokazilom o tehnični brezhibnosti vozila, ki se izda $\vee$ postopku tehničnega pregleda. Le-tega izvajajo pravne osebe, ki jih za to pooblasti minister, pristojen za notranje zadeve, medtem ko registracijo, izdajanje prometnih dovoljenj in podaljševanje njihove veljavnosti izvajajo upravne enote in t. i. pooblaščene organizacije, tj. organizacije, ki opravljajo tehnične preglede motornih in priklopnih vozil in gospodarske družbe in samostojni podjetniki posamezniki, ki opravljajo dejavnost prodaje motornih oziroma priklopnih vozil, ki jih z javnim pooblastilom določi minister, pristojen za notranje zadeve (1. odst. 205. člena in 1. odst. 193. člena ZVCP-1-UPB4).

pri vodenju upravnih postopkov in stroškov porabnikov storitev, zagotoviti večjo učinkovitost delovanja sistema, približati storitve občanom oziroma sistem registracije narediti prijaznejši uporabniku " in "Z ukinitvijo krajevnih pristojnosti ter vezavo registrskih tablic na vozilo ter drugih poenostavitvah postopkov pri registraciji vozila se bodo za uporabnike teh storitev bistveno zmanjšali stroški postopkov, saj se bodo lahko vse storitve opravljale na enem mestu " (obrazložitev predloga ZVCP-1 z dne 29. 1. 2004, Poročevalec DZ, 2004, str. 8, 10 in 41), "/.../ cilji predlagane spremembe zakona (so) usmerjene k uresničevanju antibirokratskega programa. Temeljni cilj je poenostaviti postopke registracije vozil in jih približati državljanom. /.../ Z vpisom podatkov $\vee$ prometno dovoljenje bi postopek poenostavili in znižali stroške" (obrazložitev predloga ZVCP-1A z dne 10. 2. 2005, Poročevalec DZ, 2005, str. 4), "Osnovni razlog za predlagane spremembe /.../ je poenostavitev postopkov za državljane", "cilji predlagane spremembe zakona usmerjeni k uresničevanju protibirokratskega programa, $\checkmark$ smislu poenostavitve postopkov registracije motornih vozil in zmanjšanju stroškov « (predlog zakona o spremembah in dopolnitvah zakona o varnosti cestnega prometa z dne 22. 3 . 2006, str. 1 in 2).

3 Ur. I. RS, št. 133/2006.

4 Za druge možnosti glej 190. člen ZVCP-1-UPB4.

5 Tehnični pregled ni obvezen za vsa vozila - glej 194. in 211. člen ZVCP-1-UPB4. 
Primož Pevcin, Iztok Rakar

Privatizacija na področju varnosti cestnega prometa primer prometnih dovoljenj

\subsection{Vključevanje zasebnega sektorja}

Iz predstavitve veljavne pravne ureditve je razvidno, da v postopkih preverjanja izpolnjevanja pogojev za udeležbo vozil $\vee$ prometu sodeluje tudi zasebni sektor. Razvojno gledano je najprej prišlo do pooblaščanja na področju tehničnih pregledov (Kovač, 2006, str. 325), zaradi poenostavitve postopka in njegove večje "prijaznosti do strank pa so se nato na te organizacije prenesle tudi klasične oblastne naloge, s katerimi je država ugotovila oziroma potrdila tehnično brezhibnost vozila in dovolila njegovo udeležbo $v$ prometu (prometna dovoljenja). ${ }^{6}$ Vključevanje zasebnega sektorja je torej posledica želje po javnofinančnih prihrankih in uveljavljanju načela usmerjenosti k uporabniku, katerega sestavni del je odprava administrativnih ovir (t.i. antibirokratski program).

Sedaj veljavna pravna ureditev vrst postopkov, povezanih z registracijo vozil, in možnost vljučevanja pravnih subjektov zasebnega prava, je prikazana $v$ tabeli $1^{7}$

Pravno gledano gre pri prenosu upravnih nalog na subjekte, ki niso del državne uprave, za javno pooblastilo. Javno pooblastilo je ustavnopravni institut, kajti Ustava RS $v$ 121. členu določa, da lahko pravne ali fizične osebe $z$ zakonom ali na njegovi podlagi dobijo javno pooblastilo za opravljanje določenih nalog državne uprave. Vrste nalog državne uprave na splošno opredeljuje Zakon o državni upravi (ZDU-1-UPB4), konkretne upravne naloge, ki se prenašajo $z$ javnim pooblastilom, pa so opredeljene $s$ področno zakonodajo. ZDU-1-UPB4 natančneje določa pogoje, pod katerimi je mogoč prenos upravnih nalog, in sicer če se s tem omogoča učinkovitejše in smotrnejše opravljanje upravnih nalog, kot bi bilo opravljanje nalog $v$ upravnem organu, zlasti če se lahko opravljanje upravnih nalog $v$ celoti ali pretežno financira $z$ upravnimi taksami oziroma s plačili uporabnikov, ali če glede na naravo oziroma vrsto nalog ni potreben ali ni primeren stalen neposredni politični nadzor nad opravljanjem nalog. $V$ primeru, ko se javno pooblastilo podeli na podlagi zakona, mora v skladu s stališči teorije, ki jih je sprejelo tudi Ustavno sodišče RS, zakon določiti pogoje, ki jih mora izpolnjevati nosilec javnega pooblastila, organ, ki podeli javno pooblastilo oz. določi nosilca/e javnega pooblastila, in postopek za podelitev javnega pooblastila. ${ }^{8}$

6 Kozina in Pavlič (2006, str. 8) navajata, da prenos pooblastil na območju Slovenije sega v leto 1952, ko je bil sprejet pravilnik o registraciji motornih vozil in avtomobilskih priklopnikov. 7 Tabela predstavlja nabor nalog, za izvajanje katerih minister lahko podeli javno pooblastilo (glej 2. člen Pravilnika o registraciji motornih in priklopnih vozil, Ur. I. RS, št. 66/2005 in 48/2006).

8 Glej Pirnat, 2004 in odločbo št. U-I-137/01 z dne 11. 12. 2003. 
Primož Pevcin, Iztok Rakar

Privatizacija na področju varnosti cestnega prometa primer prometnih dovoljenj

Tabela 1: Postopki, povezani z registracijo vozil in njihovi izvajalci

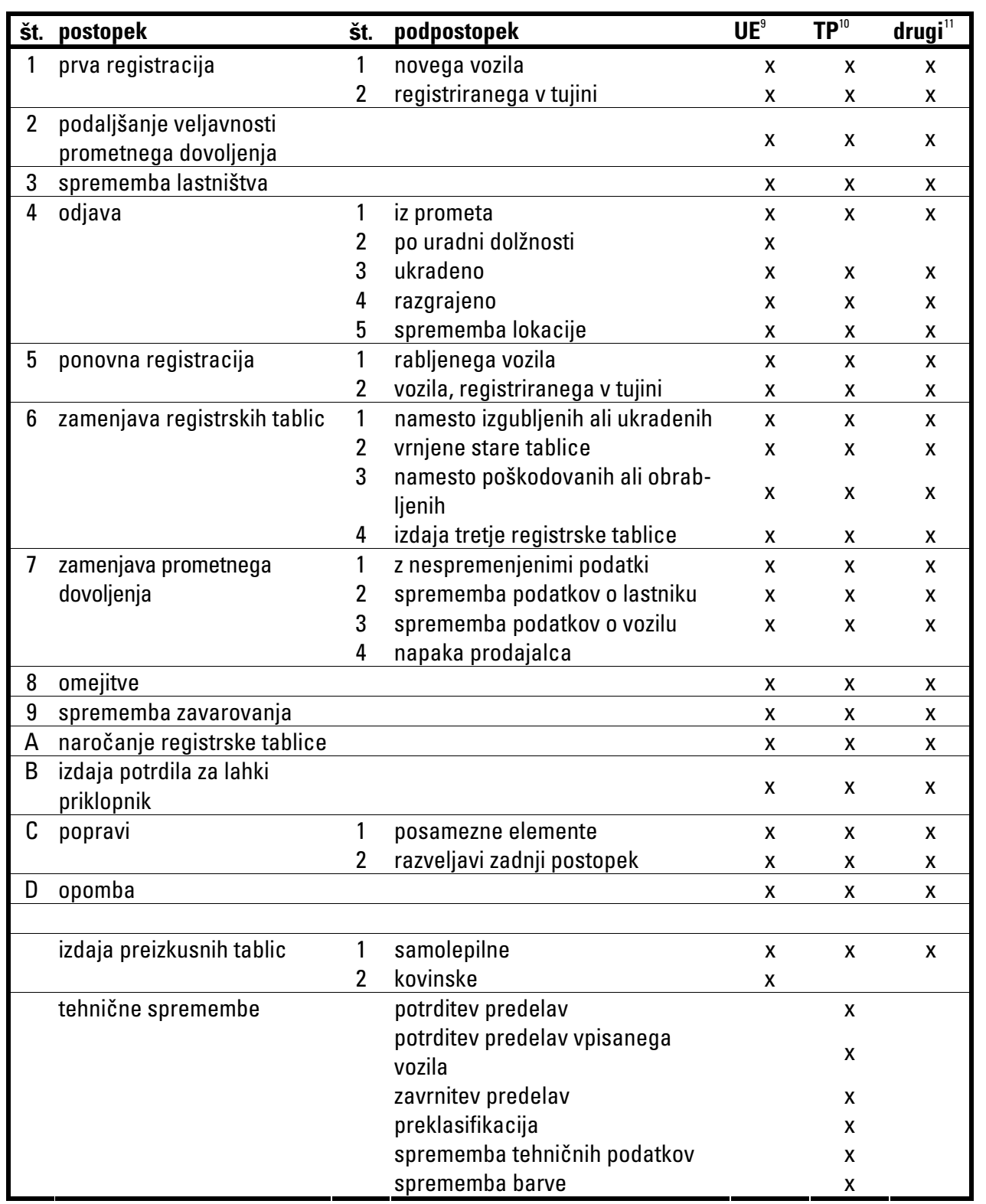

Vir: Priloga št. 2 Pravilnika o registraciji motornih in priklopnih vozil, Ur. I. RS, št. 66/2005 in 48/2006. Legenda: $\mathrm{X}$ - subjekt, ki lahko izvaja to nalogo.

9 Upravne enote.

10 Pooblaščene organizacije, ki opravljajo tehnične preglede vozil (po ZVCP-1-UPB4 so to lahko le pravne osebe).

11 Gospodarske družbe in samostojni podjetniki posamezniki, ki opravljajo dejavnost prodaje vozil. 


\section{Primož Pevcin, Iztok Rakar \\ Privatizacija na področju varnosti cestnega prometa - primer prometnih dovoljenj}

Slednji je zelo pomemben $v$ primeru, ko je po naravi stvari javno pooblastilo mogoče podeliti le omejenemu številu subjektov, saj mora biti vsem subjektom omogočeno, da se pod enakimi pogoji potegujejo zanj - $v$ nasprotnem primeru bi namreč kršili načelo enakosti pred zakonom. Kar se postopka tiče, ZDU-1UPB4 določa, da če zakon dopušča, da za pridobitev javnega pooblastila kandidira več fizičnih oziroma pravnih oseb, se izbira opravi na javnem natečaju, pri čemer je določeno, da se do uveljavitve zakona, ki bo uredil postopek podelitve javnega pooblastila, za te postopke smiselno uporabljajo določbe zakona, ki ureja javna naročila.

Naloge oziroma funkcije državne uprave se pravno gledano lahko izvršujejo na tri načine, in sicer z izdajanjem splošnih pravnih aktov, z izdajanjem posamičnih pravnih aktov in $z$ opravljanjem materialnih dejanj. Vse te oblike izvajanja upravnih nalog so tudi oblike izvajanja javnih pooblastil, pri čemer pri vsaki od teh prihaja do težav pri identifikaciji, torej pri vprašanju, ali gre $v$ konkretnem primeru za upravno nalogo in s tem za javno pooblastilo ali ne. To je razvidno tako iz prakse Ustavnega sodišča RS kot iz področne zakonodaje - kot bomo videli, področje varnosti cestnega prometa pri tem ni nobena izjema. ${ }^{12}$

\subsection{Nekatere terminološke pomanjkljivosti pozitivno- pravne ureditve}

Osnovna težava identifikacije javnih pooblastil je torej $v$ interpretaciji pojma "upravna naloga «. Zagata zakonodajalca pri opredelitvi pravne narave prenosa izvajanja določene dejavnosti na subjekte izven državne uprave se zrcali v uporabi izrazov, ki to vprašanje puščajo odprto. Tak primer je tudi ZVCP-1UPB4. Le-ta namreč pri pooblastilu za registracijo oziroma izdajo in podaljševanje prometnega dovoljenja uporablja besedno zvezo "javno pooblastilo", pri prenosu nalog tehničnega pregleda pa zgolj besedo "pooblastilo«. Vprašanje je, ali gre tudi v tem primeru za javno pooblastilo ali ne? Menimo, da je tehnični pregled mogoče šteti za upravno nalogo $v$ smislu 121. člena ustave, zato gre tudi $v$ tem primeru za javno pooblastilo. Tehnični pregled je namreč ena od ključnih faz postopka, $v$ katerem se odloča o udeležbi vozila

12 Več o problemih identifikacije javnih pooblastil glej v Pirnat, 2004, str. 1365 sl. in Kovač, 2005 , str. $225 \mathrm{sl}$. 


\section{Primož Pevcin, Iztok Rakar \\ Privatizacija na področju varnosti cestnega prometa - primer prometnih dovoljenj}

$\checkmark$ prometu. ${ }^{\mathbf{1 3}}$ Gre za fazo ugotavljanja dejstev $v$ upravnem postopku izdaje oziroma podaljšanja veljavnosti prometnega dovoljenja, $v$ skladu z zakonsko predvidenimi oblikami delovanja upravnih organov oziroma nosilcev javnih pooblastil pa za (neoblastni) materialni oziroma realni akt (glej 2. odst. 9. člena ZDU-1UPB4 in Kovač, 2006, str. 244). Zaradi tesne povezanosti te neoblastne strokovne naloge z upravnim odločanjem, torej z oblastno nalogo, je mogoče trditi, da gre za dejavnost, ki bi jo lahko opredelili kot sestavni del upravne naloge oziroma naloge državne uprave $v$ smislu 121. člena ustave. To pa nadalje pomeni, da gre pri prenosu te naloge na subjekte, ki niso del državne uprave, za obliko javnega pooblastila, in sicer za javno pooblastilo za opravljanje neoblastnih materialnih oziroma realnih aktov (primerjaj Bugarič, 2002, str. 20, Kovač, 2006, str. 244 in 325 - 326, odločbo Ustavnega sodišča RS št. U-I-305/94 in odločbo Upravnega sodišča RS, št. U 823/2000 z dne 19. 6. 2002). ${ }^{\mathbf{1 4}}$

Pregled ZVCP-1 in kasnejših sprememb pokaže, da je bilo takih zagat več. ZVCP-1 iz leta 2004 je namreč pri številnih nalogah s področja svojega urejanja predvideval vključevanje subjektov, ki niso del državne uprave, pri čemer pa je uporabljal zelo različne izraze - pooblastilo, javno pooblastilo, dovoljenje in koncesija. Za lažjo ponazoritev navajamo naslednje primere: (1) pregled ustreznosti vozila za vožnjo z zakonsko določeno hitrostjo je npr. opravila organizacija, ki je bila pooblaščena za opravljanje tehničnih pregledov motornih in priklopnih vozil (3. odst. 34. člena); (2) organizacija, ki opravlja tehnične preglede, je imela za to dejavnost podeljeno koncesijo (5. odst. 205. člena); (3) za izvajanje programa varne vožnje pri dodatnem usposabljanju voznika začetnika je fizična oseba pod zakonsko določenimi pogoji lahko pridobila dovoljenje (1. odst. 141. člena); (4) za registracijo vozil pa so poleg upravnih enot pristojne tudi organizacije, ki opravljajo tehnične preglede motornih in priklopnih vozil, ter gospodarske družbe in samostojni podjetniki posamezniki, ki opravljajo dejavnost prodaje motornih

13 Pomen te faze postopka za varnost cestnega prometa raste s starostjo vozila, zato je razumljivo, da v skladu z veljavno zakonodajo pogostnost tehničnih pregledov raste s starostjo vozila. 14 Gre za podoben primer kot pri opravljanju strokovnih nalog v okviru inšpekcijskega nadzorstva, ki jih teorija prav tako šteje kot primer javnega pooblastila. Gre namreč za strokovne, neoblastne naloge, pravno gledano za materialna dejanja, ki so podlaga za potencialno izvrševanje prisile, ki je bistven sestavni del inšpekcijskega nadzora (glej Kovač, 2005, str. 264-265). V primeru izdaje prometnega dovoljenja sicer ne gre za inšpekcijski postopek, gre pa kljub temu za postopek preverjanja izpolnjevanja določenih pogojev, med drugim tehničnih standardov, ki jih za vozilo predpisuje zakon oziroma podzakonski predpis. Tehnični pregled je tako mogoče šteti za obliko nadzora $v$ širšem smislu. Tesna povezanost tehničnih pregledov s postopkom registracije je razvidna tudi iz ZVCP-1-UPB4, ki določa, da je eden izmed pogojev za podelitev pooblastila za opravljanje tehničnih pregledov izpolnjevanje pogojev za opravljanje registracije (205. člen ZVCP1-UPB4). Da gre pri pooblastilu za opravljanje tehničnih pregledov za javno pooblastilo, je bilo tudi stališče predstavnice zakonodajnopravne službe Državnega zbora RS pri obravnavi predloga sprememb in dopolnitev zakona o varnosti cestnega prometa (ZVCP-1A) (glej Poročevalec DZ, št. 16, z dne 12. 3. 2005, str. 34). 
Primož Pevcin, Iztok Rakar

Privatizacija na področju varnosti cestnega prometa primer prometnih dovoljenj

oziroma priklopnih vozil, ki jih z javnim pooblastilom določi minister, pristojen za notranje zadeve (1. odst. 193. člena). V prehodnih določbah je določil, da pooblastila, izdana organizacijam na podlagi starega zakona o varnosti cestnega prometa $(\mathrm{ZVCP})^{\mathbf{1 5}}$, ostanejo $\vee$ veljavi do izdaje novih pooblastil oziroma do sklenitve koncesijskih pogodb (266. člen), pri čemer je bil minister, pristojen za notranje zadeve, dolžan organizacijam, ki so imele na dan uveljavitve ZVCP-1 pooblastilo za opravljanje registracije motornih in priklopnih vozil, $v$ določenem roku izdati javno pooblastilo za opravljanje teh nalog, organizacije, ki so bile pooblaščene za opravljanje tehničnih pregledov motornih in priklopnih vozil, pa so smele opravljati registracijo na podlagi pooblastila iz ZVCP najdalj eno leto od uveljavitve ZVCP-1 (267. člen) - po tem bi morale v skladu z novim zakonom pridobiti koncesijo. Taka ureditev na področju tehničnih pregledov pa ni veljala dolgo, kajti že naslednje leto je bil zakon spremenjen in dopolnjen (ZVCP-1A). Na področju tehničnih pregledov poslej ni šlo več za koncesije, ampak (spet) za pooblastila (14., 15., 17. in 20. člen ZVCP-1A). Kasnejše spremembe ZVCP-1 na tem področju niso prinesle sprememb, tako da je sedaj zakonska ureditev naslednja: za postopke registracij (in izdaje oziroma podaljševanja prometnega dovoljenja) ${ }^{\mathbf{1 6}}$ minister, pristojen za notranje zadeve, podeli javno pooblastilo, za izvajanje tehničnih pregledov pa (po zakonski dikciji) pooblastilo. ${ }^{\mathbf{7}}$

Nejasno je tudi razmerje med postopki registracije vozila, izdaje prometnega dovoljenja in podaljševanja veljavnosti prometnega dovoljenja. Po zakonski dikciji je namreč registracija zgolj vpis podatkov $v$ evidenco, torej realni akt (1. odst. 192. člena ZVCP-1-UPB4) ${ }^{\mathbf{1 8}}$. Registraciji nato sledi izdaja prometnega dovoljenja, torej upravnopravni akt (odločba) (glej 6. odst. 194. člena ZVCP-1UPB4). ${ }^{\mathbf{1 9}}$ Iz tega izhaja da gre za zaporedni fazi in za pravno gledano dve različni vrsti dejanj. Slednje pomeni, da bi država morala podeliti dve različni vrsti javnih

15 Uradni list RS, št. 30/98, 33/2000 - odl. US, 39/2000 - popr. odl. US, 61/2000, 100/2000 odl. US, 21/02 in 67/02.

16 6. odst. 194. člena v povezavi s 1. odst. 193. člena ZVCP-1-UPB4.

$17 \vee$ zvezi s predstavljenimi cilji zakonodajnih sprememb je utemeljeno vprašanje, kakšne so negativne posledice tako hitrih in obsežnih sprememb $v$ tako kratkem času - le-te so namreč povzročile nestabilnost pravnega okvira delovanja uporabnikov vozil, pristojnih organov in pooblaščenih subjektov, kar je nedvomno strošek, pa čeprav ga je težko finančno ovrednotiti. Ob tem se lahko vprašamo, ali so bile pred predlaganimi spremembami ustrezno preučene vse možne posledice in vse vrste stroškov, ki jih bo sprememba prinesla. Gre za t.i. RIA oziroma oceno vplivov predpisov, ki je od sprememb poslovnika vlade leta 2006 dalje v Sloveniji celoviteje urejena.

18 Evidenco registriranih vozil vodi ministrstvo, pristojno za notranje zadeve, podatke pa vnašajo registracijske organizacije (2. odst. 202. člena ZVCP-1-UPB4).

$19 \mathrm{lz}$ zakona ni povsem jasno razvidno, ali je dokazila, ki so potrebna za registracijo in posledično izdajo prometnega dovoljenja, potrebno predložiti tudi za podaljšanje prometnega dovoljenja - to določa šele podzakonski predpis (glej 6. in 11. člen Pravilnika o registraciji motornih in priklopnih vozil, Ur. I. RS, št. 66/2005 in 48/2006). 
pooblastil - za opravljanje realnih aktov in za izdajanje posamičnih upravnih aktov. Obe vrsti nalog sta sicer res med seboj tesno povezani, kar utemeljuje tudi njuno izvedbo pri istem subjektu, vendar to ne bi smel biti razlog, da zakon govori zgolj o javnem pooblastilu za registracijo vozila, pri čemer pa je očitno mišljeno tudi pooblastilo za izdajo oziroma celo podaljševanje prometnega dovoljenja. Da je temu tako, lahko sklepamo tudi iz podzakonskega predpisa, ki med upravnimi postopki izdaje prometnega dovoljenja sploh ne omenja - predvideni so postopki prve in ponovne ${ }^{\mathbf{2 0}}$ registracije ter podaljšanja veljavnosti prometnega dovoljenja in zamenjava ${ }^{21}$ prometnega dovoljenja. Tudi pregled spletnih strani pooblaščenih organizacij razkriva, da se pod pojmom registracija razume tudi izdajo prometnega dovoljenja, temu ustrezno pa se namesto izraza podaljševanje prometnega dovoljenja uporablja besedna zveza "podaljševanje registracije «. ${ }^{\mathbf{2 2}}$ Menimo, da je taka ureditev premalo jasna in zato v nasprotju z načelom pravne države. Pri javnih pooblastilih gre namreč za določanje pristojnosti, zato bi morale biti te zakonske določbe $v$ skladu $z$ načelom jasnosti in določnosti, ki je izvedeno iz načela pravne države, čim bolj jasne.

\section{Nekateri ekonomski vidiki privatizacije}

\subsection{Privatizacija javnega sektorja kot koncept spreme- njene ekonomske vloge države}

Javnofinančne omejitve, katerim je danes izpostavljena večina razvitih držav, botrujejo tudi zahtevam po spremenjeni ekonomski vlogi države $v$ sodobnih družbah, kar zahteva $v$ praksi tudi uvedbo nekaterih reformnih procesov $v$ javnem sektorju, med katere spada tudi privatizacija javnega sektorja. Omeniti velja, da se $v$ tem kontekstu čedalje bolj uveljavlja koncept delne ali kvazi privatizacije, ki v ekonomskem smislu opredeljuje vpeljavo zasebnega sektorja $v$ javni sektor s sklepanjem pogodb in opravljanjem pogodbenih del ter pomeni vmesno obliko med državno in zasebno lastnino. Med metode delne privatizacije javnega sektorja lahko štejemo tudi pogodbeništvo z zasebnim sektorjem, katerega cilj je regulirati odnose med "kupci« in "prodajalci« v javnem sektorju

20 Ta se npr. opravi, če je bilo vozilo odjavljeno iz prometa.

21 Ta se npr. opravi, če se spremenijo podatki o lastniku vozila.

22 Glej prilogo št. 1 pravilnika o registraciji motornih in priklopnih vozil, Ur. I. RS, št. 66/2005 in 48/2006 in http://www.amzs.si/?podrocje=213/media- um.si/interservice/registracija_tex.htm, http://www.tehnicnipregledi-kranj.si/upravni_postopki.php. 
Primož Pevcin, Iztok Rakar

Privatizacija na področju varnosti cestnega prometa primer prometnih dovoljenj

z uporabo tržnih mehanizmov, kar naj bi pripeljalo do večje učinkovitosti v javnem sektorju. $\vee$ praksi zajema pogodbeništvo z zasebnim sektorjem najpogosteje področje podeljevanja koncesij in javnih pooblastil. Eden od ciljev delne privatizacije je prehod k minimalistični »nakupovalni državi«, kjer javni sektor nastopa v čim večji meri v vlogi »inteligentnega potrošnika ${ }^{\mathbf{2 3}}$

\section{2 Študij primera s področja privatizacije upravnih nalog v Sloveniji - primer prometnega dovoljenja za motorna vozila}

Registracijo vozil v Sloveniji opravljajo naslednje registracijske organizacije: upravne enote, pooblaščene organizacije, ki opravljajo tehnične preglede vozil ( $v$ nadaljevanju: tehnične baze), in pooblaščene organizacije, ki opravljajo dejavnost prodaje vozil (gospodarske družbe in samostojni podjetniki posamezniki), ${ }^{\mathbf{2 4}}$ pri čemer nadzor nad njihovim delom vrši Ministrstvo za notranje zadeve. $^{\mathbf{2 5}}$ Vprašanje, ki se pojavlja, je, koliko uporabnikov pridobi oziroma podaljša veljavnost prometnega dovoljenja na posamezen način. $V$ spodnji tabeli so tako prikazani vzorčni podatki po namenu izdaje in razlogu podaljšanja prometnega dovoljenja pri upravnih enotah in pooblaščenih organizacijah za obdobje od 6. 3. do 19. 4. 2006.

23 Več o tem glej Wilson in Doig (1998) ter Greve (2000).

$24 \mathrm{~V}$ Sloveniji ima koncesijo (oziroma pravnoformalno bolj pravilno javno pooblastilo) Ministrstva za notranje zadeve za izvedbo del in nalog z navedenega upravnega področja 72 organizacij. Tehnične baze poleg izdaje oz. podaljšanja prometnega dovoljenja opravljajo še tehnične preglede, medtem ko prodajalci vozil opravljajo za stranko le storitev izdaje prometnega dovoljenja (in registrskih tablic) ob nakupu novega vozila. Po novem (približno od sredine leta 2006) pa je možno podaljšanje veljavnosti prometnega dovoljenja (z določenimi omejitvami) izvesti tudi prek spletnega portala e-uprave. 25 Omeniti velja, da obstaja razlika med taksami oz. plačilom za opravljeno storitev izdaje in podaljšanja prometnega dovoljenja med upravnimi enotami in pooblaščenimi organizacija$\mathrm{mi}$, ki opravljajo enako storitev. Tako upravne enote zaračunavajo za dejanja $\mathrm{v}$ upravnih postopkih upravne takse po taksnih tarifah Zakona o upravnih taksah. V letu 2006 je tako uporabnika izdaja prometnega dovoljenja pri upravnem organu stala skupaj 3685 SIT, podaljšanje veljavnosti prometnega dovoljenja pa 1360,00 SIT (enako višino takse za podaljšanje so morali plačati tudi uporabniki, ki so podaljšali veljavnost prometnega dovoljenja prek spletnega portala e-uprave, pri čemer pa je treba tu zraven prišteti še strošek obrazca novega prometnega dovoljenja, saj mora uporabnik staro prometno dovoljenje (osebno ali po pošti) vrniti upravni enoti. Po drugi strani pa pooblaščene organizacije navedene storitve uporabnikom zaračunavajo po posebnem ceniku storitev, pri čemer je $v$ letu 2006 storitev izdaje prometnega dovoljenja uporabnika stala 3773 SIT (z DDV), storitev podaljšanja pa 1460 SIT (z DDV) (več o tem glej Jerovšek et al., 2006). 
Primož Pevcin, Iztok Rakar

Privatizacija na področju varnosti cestnega prometa primer prometnih dovoljenj

Tabela 2: število opravljenih poslov na področju prometnih dovoljenj po namenu in izdajatelju v Sloveniji v obdobju 6. 3. - 19. 4. $2006^{26}$

\begin{tabular}{|l|c|c|}
\hline $\begin{array}{c}\text { Razlog izdaje oz. podaljšanja veljavnosti } \\
\text { prometnega dovoljenja }\end{array}$ & Upravne enote & Pooblaščene organizacije \\
\hline $\begin{array}{l}\text { 1. Podaljšanje veljavnosti prometnega } \\
\text { dovoljenja }\end{array}$ & 5476 & 161341 \\
\hline 2. Prva registracija & 1874 & 14300 \\
\hline 3. Sprememba lastništva & 4053 & 16485 \\
\hline 4. Ponovna registracija & 2635 & 17446 \\
\hline 5. Zamenjava registrskih tablic & 1814 & 1537 \\
\hline 6. Zamenjava prometnega dovoljenja & 1585 & 1820 \\
\hline 7. Vpis omejitve & 573 & 273 \\
\hline 8. Vpis opombe & 1186 & 213361 \\
\hline Skupaj & 19196 & \\
\hline
\end{tabular}

Vir: glej Jerovšek et al. (2006).

Podatki v zgornji tabeli kažejo, da je bilo v vzorčnem obdobju v Sloveniji skupaj opravljenih 232557 storitev s področja izdaje oziroma podaljšanja veljavnosti prometnih dovoljenj, pri čemer so skoraj $92 \%$ teh storitev opravile pooblaščene organizacije, kar priča o precejšnji prednosti le-teh pri opravljanju teh storitev, ne glede na to, da so njihove storitve v povprečju dražje. Na primer, pri opravljanju storitev podaljšanja veljavnosti prometnega dovoljenja (točka 1) je prednost pooblaščenih organizacij še večja, saj je bilo v navedenem obdobju opravljenih skupaj 166817 storitev podaljšanja veljavnosti dovoljenja, pri čemer so pooblaščene organizacije opravile kar več kot 96 \% vseh podaljšanj. Analiza obstoječega stanja je tako pokazala, da velika večina uporabnikov storitve povezane z pridobitvijo oziroma podaljšanjem prometnega dovoljenja za motorna vozila opravi pri pooblaščenih organizacijah. Razlogov za takšno stanje je več, pri čemer prednosti očitno odtehtajo višjo ceno tako opravljene storitve. Prednost za uporabnike je namreč ta, da lahko storitev opravijo na enem mestu, saj lahko hkrati opravijo več storitev, ki se zahtevajo pri pridobivanju oziroma podaljševanju veljavnosti prometnega dovoljenja (npr. hkrati lahko sklenejo obvezno avtomobilsko zavarovanje, plačajo nadomestilo za uporabo cest ter opravijo tehnični pregled vozila).

26 Vir podatkov je Matični register vozil - centralna evidenca, april 2006. 


\section{Primož Pevcin, Iztok Rakar \\ Privatizacija na področju varnosti cestnega prometa - primer prometnih dovoljenj}

Glede na zgoraj navedeno se pojavlja vprašanje o smiselnosti ohranjanja obstoječega hibridnega sistema, ko se ena in ista storitev opravlja na dva različna načina (na upravni enoti in pri pooblaščenih organizacijah - nosilcih javnega pooblastila). Namreč, za državo bi bilo racionalno, da omogoči opravljanje storitve na en sam način, in sicer prek pooblaščenih organizacij. Takšen način opravljanja storitev prinaša uporabnikom prednost, da lahko storitev pridobijo na enem samem mestu. Glede na dejstvo, da veliko večino storitev, vezanih na prometno dovoljenje, opravijo pooblaščene organizacije, bi državni organi lahko prenehali opravljati to dejavnost $v$ celoti ${ }^{\mathbf{2 7}}$, smiselno bi bilo le ohraniti nadzorno funkcijo za ohranitev kakovosti in legalnosti opravljanja storitev, kar pa je mogoče doseči tudi s konkurenco in razširitvijo kroga pooblaščenih organizacij. ${ }^{\mathbf{2 8}}$

27 Omeniti velja, da bi popolna privatizacija na navedenem področju imela tudi implicitne pozitivne fiskalne učinke $v$ obliki posredno pridobljenih sredstev. $\mathrm{Na}$ primer, na podlagi vzorčnih podatkov iz tabele 2 lahko izračunamo, da je oportunitetni strošek hibridnega načina izvajanja storitev (oziroma neizvedene popolne privatizacije) za obdobje 45 dni samo pri storitvi podaljšanja veljavnosti prometnega dovoljenja 5.560,31 eurov (1.332.475 SIT), kar predstavlja vsoto izgubljenega davka na dodano vrednost, ki bi ga država direktno pridobila, če bi se ta storitev $v$ celoti opravljala le pri pooblaščenih organizacijah. Na letni ravni bi $v$ grobem po premo sorazmernem izračunu ta oportunitetni strošek znašal približno 46.000 eurov (11 milijonov SIT). Po drugi strani takšen način izvajanja storitev prinaša državi še to prednost, da pooblaščene organizacije dejansko kreditirajo državo, saj plačevanje upravnih taks dejansko poteka tako, da pooblaščena organizacija vnaprej nabavi in plača kolke. Hkrati je storitev tudi relativno poceni za državo (gledano iz vidika, koliko stroškov država implicitno prizna pooblaščeni organizaciji pri taksi), saj je zaslužek pooblaščenih organizacij pri upravnih taksah $10 \%$.

28 Nenazadnje, vprašanje, ki se pojavlja, je, kakšne so značilnosti in učinki sodobnega elektronskega izvajanja storitev, ki jih državni aparat izvaja prek spletnega portala e-uprava. Namreč, med storitve slovenske državne uprave spada po novem, hkrati z obstoječo možnostjo izvajanja storitve s »klasičnim « upravnim poslovanjem, tudi možnost spletnega (elektronskega) podaljšanja veljavnosti prometnega dovoljenja za vozila, ki jim ni treba opraviti tehničnega pregleda (glej Državni portal e-uprava, 2006 in 194.b člen ZVCP-1-UPB4). Tako se lahko dejansko veljavnost prometnega dovoljenja podaljša za vozila, ki so že registrirana in jim je veljavnost potekla pred manj kot 30 dnevi ali imajo veljavno prometno dovoljenje še največ $30 \mathrm{dni}$, ob pogoju, da imajo veljaven tehnični pregled. $V$ takem primeru uporabnik potrebuje le številko prometnega dovoljenja, številko veljavne police obveznega zavarovanja, plačilno sredstvo (kreditno kartico) in dostop do interneta. Problem je $v$ tem, da takšne storitve ni možno opraviti na enem mestu, saj obveznega avtomobilskega zavarovanja ni možno skleniti na enak način ( $v$ najboljšem primeru je še vedno potrebno čakati na polico, ki pride po pošti, četudi zavarovalnica že omogoča elektronsko sklenitev obveznega zavarovanja), hkrati pa uporabnik veljavno (podaljšano) prometno dovoljenje še vedno dobi le po pošti ( $z$ vročitvijo), pri čemer pa mora staro prometno dovoljenje (bodisi po pošti ali osebno) vrniti upravni enoti. Poleg tega te storitve ni mogoče opraviti za vozila, ki potrebujejo tehnični pregled (torej za vozila, ki so skladno z novo ureditvijo stara 4, 6, 8 ali več let), nenazadnje pa uporabnik potrebuje tudi dostop do interneta (kar lahko pomeni zanj dodaten strošek računalniške in telefonske opreme), zaradi "neosebnega" (elektronskega) izvajanja storitve pa mora vsakič pridobiti tudi nov obrazec prometnega dovoljenja. 


\section{Primož Pevcin, Iztok Rakar \\ Privatizacija na področju varnosti cestnega prometa - primer prometnih dovoljenj}

\section{Zaključek}

Podatki o številu opravljenih storitev izdajanja in podaljšanja veljavnosti prometnega dovoljenja za motorna vozila $\vee$ Sloveniji so pokazali, da velika večina uporabnikov to storitev opravi pri pooblaščenih organizacijah. Razlogov za takšno stanje je več, pri čemer velja omeniti enostavnost storitve in nižje stroške za uporabnika (namreč, storitev lahko opravi na enem mestu, kar pomeni tudi nižje oportunitetne stroške zaradi manj izgubljenega časa). Nenazadnje, takšen način izvajanja storitev ima tudi pozitivne učinke za državo, saj ji prinaša implicitne prihodke od zaračunanega in pobranega davka na dodano vrednost od pooblaščenih organizacij, hkrati pa ima tudi pozitivne poslovne učinke za pooblaščene organizacije, saj gre za komplementarno dejavnost, ki jim lahko pospešuje prodajo tudi pri drugih dejavnostih (na primer pri prodaji vozil). Sklenemo lahko, da je glede na obstoječe stanje razvitosti storitev za uporabnika optimalno, da storitev pridobitve oziroma podaljšanja veljavnosti prometnega dovoljenja opravi pri pooblaščeni organizaciji, kar govori $\vee$ prid privatizaciji na navedenem področju.

Dr. Primož Pevcin je doktor ekonomskih znanosti. V svojem raziskovalnem delu se ukvarja pretežno s proučevanjem ekonomskih vidikov politike in prava, $v$ pedagoškem delu na Fakulteti za upravo pa sodeluje pri izvedbi predmetov Temelji ekonomije in Ekonomika javnega sektorja.

Iztok Rakar je leta 1998 diplomiral s področja upravnega prava. Leta 1999 se je zaposlil kot sodniški pripravnik na Višjem sodišču v Ljubljani, leta 2000 pa kot asistent za upravnopravno področje na Visoki upravni šoli v Ljubljani, leto kasneje se je vpisal na podiplomski študij javne uprave na Pravni fakulteti v Ljubljani ter istega leta opravil strokovni izpit za zaposlene $v$ državni upravi, leto kasneje pa tudi pravosodni izpit (državni pravniški izpit). Leta 2004 je magistriral na Pravni fakulteti v Ljubljani in dve leti zatem postal doktorski kandidat na Pravni fakulteti Univerze v Ljubljani z naslovom doktorske disertacije Vključevanje javnosti $v$ delovanje izvršilne veje oblasti pri sprejemanju splošnih pravnih aktov $v$ Republiki Sloveniji pod mentorstvom prof. dr. Rajka Pirnata in somentorstvom izr. prof. dr. Gregorja Viranta. 
Primož Pevcin, Iztok Rakar

Privatizacija na področju varnosti cestnega prometa primer prometnih dovoljenj

\section{Literatura in viri}

- Bugarič, B. (2002): Prenos izvrševanja javne oblasti, Slovenska uprava, let. 2, št. 1, str. $19-20$.

- Bugarič, B. et al. (2004): Komentar zakonov s področja uprave, Inštitut za javno upravo pri Pravni fakulteti v Ljubljani, Ljubljana.

- Greve, C. (2000): Governance by contact creating public-private partnerships in Denmark. V: Fortin, Y. in Van Hassel, H. (ur.): Contracting in the New Public Management. Amsterdam: IOS Press, str. 49-66.

- Kovač, P. (2005): Javno pooblastilo v Republiki Sloveniji (doktorska disertacija), Ljubljana, Pravna fakulteta.

- Kovač, P. (2006): Pravni in sociološki vidiki javnih pooblastil, Fakulteta za upravo (Upravna misel: zbirka znanstvenih monografij), Ljubljana.

- $\quad$ Pirnat, R. (2004): Nekatera vprašanja podelitve javnega pooblastila, Podjetje in delo, let. 30, št. 6/7, str. 1365-1375.

- Rakar, I. (2004): Prenos izvajanja upravnih nalog izven državne uprave (magistrska naloga), Ljubljana, Pravna fakulteta.

- Virant, G. (2004): Prenos nalog javne uprave na nedržavne organizacije - primerjalni in teoretični vidiki, Podjetje in delo, let. 30, št. 6/7, str. 1411-1418.

- Wilson, J. in Doig, A. (1998): Bureaucratic to business like? Modelling change in local government management. V: Montanheiro, L. et.al. (ur.): Public and Private Sector Partnerships: Fostering Enterprise. Sheffield: Sheffield Hallam University, str. 667-684.

Viri

- Državni portal e-uprava. http://e-uprava.gov.si, avgust 2006 in januar 2007.

- Jerovšek, T. et al. (2006): Privatizacija upravnih nalog v Republiki Sloveniji. Zaključno poročilo internega raziskovalnega projekta. Ljubljana: Fakulteta za upravo.

- Kozina, N. in Pavlič, J. (2006): Privatizacija upravnih nalog (interni raziskovalni projekt seminarska naloga), Fakulteta za upravo, Ljubljana.

- Matični register vozil - centralna evidenca. April 2006.

- Resolucija o nacionalnem programu varnosti cestnega prometa za obdobje 2007 2011 »Skupaj za večjo varnost», osnutek, junij 2006,

http://www.mzp.gov.si/fileadmin/mzp.gov.si/pageuploads/06nacionalni_prog_varnosti_ cestnegaprom2407.pdf, 12. 10. 2006.

- Odločba Ustavnega sodišča RS št. U-I-137/01 z dne 11. 12. 2003

- Odločba Upravnega sodišča RS št. U 823/2000 z dne 19. 6. 2002

- $\quad$ http://zakonodaja.gov.si 


\section{SUMMARY}

\section{PRIVATISATION IN THE FIELD OF ROAD TRAFFIC SECURITY - THE CASE OF TRAFFIC LICENCE IN SLOVENIA}

In the last few decades road traffic has been marked by rapid technological development of vehicles and infrastructure, more complex road systems and rising traffic volumes. On the other hand, it has been marked by road accidents that cause human causalities and social-economic losses. Those are the reasons for government regulation of traffic, which is aimed at highest possible traffic security.

Important part of legal regulation of road security is legal regulation of conditions for participation of vehicles in traffic. In recent years, this part of legal regulation has been subject to rapid and frequent changes in Slovenia in recent years. The analysis of legislative proposals clearly shows that the main reasons for changes were reduction of costs, higher effectiveness of system, simplification of procedures and user-friendly orientation.

One of the basic conditions for road security as one of the main qualities of traffic system is technical faultlessness of vehicles. Because specific expert knowledge and expensive technical equipment are needed in order to verify technical faultlessness of vehicles, it is understandable that government has relatively early authorised private law entities and individuals with appropriate knowledge and equipment to perform this task. In Slovenia, it first came to the transferring of performing of technical examination of vehicles and later to the transferring of typically authoritative administrative tasks, such as permitting their participation in traffic (i.e. traffic licence), due to simplification and user-friendly orientation of the process.

From the Slovenian legal point of view the transfer of administrative tasks from administration to private law or public law entities outside the structure of state administration or to individuals represents granting of public authority or so-called "public authorization", which is a constitutional institute. These subjects are authorized directly by law (act of parliament) or by decision based on law (act of parliament) to perform certain administrative tasks. Act on State Administration defines general types of administrative tasks while other tasks are defined in other acts (e.g. Act 
Primož Pevcin, Iztok Rakar

Privatizacija na področju varnosti cestnega prometa primer prometnih dovoljenj

on Urban Planning). Act on State Administration also defines conditions for public authorization which are: 1) more efficient and expedient performance of administrative tasks in comparison to performance by administrative bodies, especially if performance of administrative tasks can be entirely (or for the most part) financed by administrative or user fees; or 2) condition where permanent and immediate political supervision over the performance of tasks is not necessary or appropriate due to their nature.

One of the main problems of public authorization is its identification in practice. Administrative tasks are (inter alia) performed by adopting regulations (delegated legislation), individual legal acts (decisions) or physical acts (e.g. pulling-down illegal building). In our opinion technical examination of vehicles and issuing permits for their participation in traffic represent two examples of administrative tasks and thus of public authorisation (physical acts and decisions). In our opinion, the current Slovenian legal regulation of this type form of public authorisation does not meet the requirements of rule of law due to the lack of precision.

Besides, in vast majority of developed countries the increased fiscal restraints nowadays are demanding changing the role of the state in the economy in the vast majority of developed countries nowadays. In this context, there has been a tendency toward privatisation of public services, especially with the method of contracting out, which describes namely the transfer of administrative tasks from administration to private law or public law entities outside the structure of state administration or to individuals. The purpose of contracting out is to reform the economic role of the state from its traditional bureaucratic role toward the role of "intelligent consumer".

In the case of traffic licence in Slovenia, it has been pointed out that contracting out of public administration tasks in the field of traffic licence issuing has caused that the majority of costumers receive their traffic licence and perform other tasks attached to traffic licence obligations at private sector entities, the major reasons being simplified procedure and lower opportunity costs. Moreover, discussed in the paper, there is no rationale that public administration entities further perform this service, since it is better performed by private sector entities. 